\title{
Line Loss Analysis of 10kV Distribution Network and Loss Reduction Measures
}

\author{
Zheng Wei ${ }^{1}$, Li Haoluan ${ }^{2}$, Qin Xiaolai ${ }^{1}$, FeiXuan ${ }^{1}$ \\ ${ }^{1}$ Yingkou Power Supply Company of National Grid Liaoning Electric Power Co., Ltd \\ ${ }^{2}$ Electrical and Electronic Engineering Institute of North China Electric Power University \\ jkweiz@sina.com, dianlilhı@163.com
}

Keywords: Distribution network; line loss; loss reduction; measures

\begin{abstract}
It firstly illustrates the meaning of studying the line loss of distribution network briefly, analyzes the main reasons influencing the line loss of distribution network subsequently and finally puts forward specific loss reduction measures. Theoretical analysis demonstrates that these measures can effectively lower the line loss of distribution network.
\end{abstract}

\section{Introduction}

Line loss management has always been the emphasis and difficulty of our company's management work, and line loss is an important economic technical index of our company and the important symbol of the operating status and management level of the power system. The main factors causing line losses involve magnetic fields, resistors, management, etc. Reducing line losses is beneficial to lowering the wastage of electric power and reaching the purpose of saving energies. The management of line losses should be emphasized and improved. With the mutual combination of professional management and mass management, the conditions of safe and economic operation of grid should be constantly improved and the completion of the line loss index given by the provincial company shall be ensured by adopting loss reduction measures.

\section{The main reasons of causing distribution network line losses}

The line loss will appear when distribution network is only in operation. In distribution network lines, reactive power equipment, transformers, meters, voltage adjusting equipment, protection devices, metering devices, transmission components and changing components are wasted inevitably. Beyond that, in the operation process of distribution network lines, steal of electricity occurs inevitably, which will cause $10 \mathrm{kV}$ distribution network line loss easily, affect the normal power supply and do harm to the long-term development of power-supply enterprises.

\section{Electric energy loss calculation in distribution network}

The calculation methods of electric energy loss calculation in distribution network are mainly divided into two categories: The first is various statistical models and nerve network models and other algorithms according to feeder data; the other category is various equivalent model algorithms established by main wasted components in network. The equivalent resistor method is more complete theoretically, which overcomes the deficiencies of numerous aspects in methods. For example, it is only related to structure parameters, the rated capacity of distribution network transformers and the resistance of sectional lines, and operating data is not needed, electric energy loss calculation can be done only by calculating equivalent resistor data, fitting to $10 \mathrm{kV}$ and below distribution network theoretical line loss calculation. Therefore, this paper takes equivalent resistor method as the example and discusses the calculation of distribution network electric power loss.

The below assumption is made to simply the calculation:

(1) The power factor $\cos \varphi$ of every load point is the same; 
(2) The total current of line is distributed to every load point in accordance with the proportion of the capacity of the distribution network transformer in the total capacity of this line distribution network capacity.

In this case, the complicated distribution network line can be simplified as an equivalent loss resistor by utilizing line parameters. This methods is called equivalent resistor method. The calculation of equivalent resistor is that: Assuming that there are $\mathrm{m}$ load points in the line, the line is divided into $n$ calculation sections, and the resistor of each section of wire are R1, R2m R3,.., Run, the additional resistor of the load current is Ret, and the basic equivalent resistor is Re. When the line structure is not changed, the values of three equivalent resistors of Re, Ret and Rees are not changed, and some operating parameters can be utilized to calculate line losses.

\section{Main factors causing excessive $10 \mathrm{kV}$ distribution network line losses}

There are multiple factors causing $10 \mathrm{kV}$ distribution network line losses, which can be concluded into two great categories of management and technology. In technology, conditions involve incomplete distribution grid structure, unreasonable operations of transformers, etc. In terms of management, the main problems are found in $10 \mathrm{kV}$ distribution network line management, and the specific analysis is as below.

\section{The consumption of distribution network}

In the operating process of distribution network lines, the condition that big horses pull a small carriage exists in the long term. For instance, in distribution network lines, the load capacity of distribution transformer is not matched with the actual electric load capacity, causing excessive consumption. In addition, in distribution network lines, the situation that the load rate of public use transformers is excessively low often appears so as to lead the overload in the peak period and the under-load in the down period. In partial assembly positions, some distribution network are biased. Beyond that, the unbalanced three phrase load problem in the low-voltage line of distribution network transformer also leads to the continual increase of neutral line current and the increasing loss.

\section{Line consumption}

Line wastage will gradually increase because of unreasonable and unscientific line designs. For example, roundabout line power supply problems widely exist in the layout of lines, which not only stretch the radius of $10 \mathrm{kV}$ distribution power supply, but also increases the power transmission distance, influencing the loss of lines seriously. In addition, excessively few power points in the middle of lines; excessively big or small line wire section, unscientific operation of $10 \mathrm{kV}$ distribution network lines and other numerous factors, and distribution network lines are at the status of empty load, light loads or overload in the operation process of distribution network lines, which will also lead to the increase of line consumption; and there are also a lot of lines that have not been updated for a long time, because of serious aging problem, current is often leaking frequently, which also leads to the increase of line loss. With the swift development of our domestic economy, people have higher requirements on the life quality. While each household appliances are bringing convenience to our life, the problem of increasing electricity loads also appears, leading that distribution network lines cannot satisfy reactive compensation and increase line losses.

\section{Incorrect measurement}

In the aspect of actual electric measurement, because of improper management of power supply enterprises, numerous metering equipment are not checked and repaired regularly, serious line loss conditions can occur easily, which is not beneficial to the long-term development of power supply enterprises and the liability of electricity consumption of users. In the aspect of actual electricity consumption measurement, meter and CT are burned to be broken, meters are chucked, PT is lost in phase, etc, causing the problems of incorrect metering, the loss of partial electric quantity, etc, and 
serious power distribution line losses are caused to bring serious economic damage to power supply enterprises.

\section{Analysis of the measures to lower the line losses of $10 \mathrm{kv}$ distribution network \\ Optimizing the grid structure of $10 \mathrm{kv}$ distribution network}

It should enhance the strength of reforming $10 \mathrm{kv}$ distribution network line project, optimize the grid structure of distribution network rationally and effectively and make distribution network line reach the perfect operating environment. Firstly, it should optimize the distribution of the power points in the distribution network line reasonably, and power points should be added in the sections where the radius of power supply line is excessively long. And the power points should be set in the center position of line loads, and the effective measure of adding power points should be done in the overload line, which can not only lower the loss of distribution network line, but also enhances the liability of the quality of the power supply of the distribution network. Besides, the three phrase load existing in the public use transformer should be optimized and adjusted reasonably and effectively, the occurrence of unbalanced three phrase loads should be possibly avoided or reduced so that the three phrase balance power supply effects can be implemented. In addition, in the condition that the drop of the peak period and low period of electricity loads is greater, the the double-circuit line power supply effects should be adopted in time so as to lower the losing rate of distribution network line better.

\section{The economic operation of transformers}

When the line loss degree leaded by transformers reaches above one third of the total wastage, it can be said that transformer is the main factor causing the increase of line loss rate in distribution network. In the normal operation of transformers, several aspects need to be noticed. Firstly, the power factors of electricity users should be improved, reactive power appearing in the working generators should be reduced or avoided, the same is to the reactive power transmitted in the operating transformers, and the ability of transformers in power transmission and supply should be improved rationally and effectively. Besides, economic operation is implemented in transformers, the reduction or avoidance of the transmission situation of reactive currents should be noticed, which can not only lower the active loss of transformers effectively, but also utilize the electric quantity in a better way.

\section{Loss reduction management}

\section{Establishing organization management system and index management system}

It should establish corresponding management system and plans the coordination of the entire grid management. The post of each level of staffs should be specified, liabilities should be implemented layer by layer and examination shall be strict. The responsible person of line loss should be set up to be in charge of management and coordination of line loss of distribution network within the operating area of the power supply administration and low-voltage distribution network. Line loss rate index guarantee system should include line loss management index, comprehensive loss index, high and low voltage passing rate index, checking rotation rate index of the electric energy meter, real coping rate index of the electric energy meter, operational rate index of compensating capacitor, customer-unit power factor index, etc. The formulation of these indexes should be scientific and reasonable and integrated to the ground layer by layer so as to guarantee the implementation of the overall indexes.

\section{Line loss analysis}

Line loss analysis is to analyze the formation situation of past line losses, discover the existing problems, develop line loss activities specifically and implement the best loss reduction effects. The methods usually adopted in line loss analysis include electric energy balance analysis, comparative 
analysis of theoretical line losses and practical line losses, the comparative analysis of the reality and the corresponding period in the history, analysis of the comparisons with the averaged level, etc, analysis should be emphasized and specified.

\section{Enhancing operating management and marketing management}

Operating management measures include: 1)adjusting the power factors of line equipment, switching and compensating the capacitor in time in accordance with the load changes.2)adjusting the line voltage and making the voltage in the qualified range and the economic operating status;3)adjusting the loading rate of the transformer and making it operate in the economic area.

\section{Conclusion}

By studying and analyzing the factors of line losses of $10 \mathrm{kV}$ distribution network and loss reduction measures, it can be known that in the maintenance process of distribution network, distribution network staffs must combine the actual situation of distribution network effectively so as to adopt corresponding maintenance measures specifically. In addition, in the working process, they need to improve their comprehensive quality and professional abilities continually so as to maintain the sustainable development better.

\section{References}

[1] Yu Xibo. Brief Discussion on the Reasons of Line Losses and its Loss Reduction Measures[J]. Guide of Technology to Fortunes, 2010(35).

[2] Li Qisen. Brief Discussion on Influencing Factors of Distribution Network Line Losses and Loss Reduction Measures[J].China Technology Information,2010(15).

[3] Liu Zhimin, Trial Discussion on Line Loss Management of 10kv Distribution Network and Related Changed Household Analysis[J].Fujian Energy Development and Economy, 2002(1).

[4] Cui Hua. Brief Analysis of Line Loss Management of 10kv Distribution Network and Loss Reduction Measures[J].Value Engineering,2010(30).

[5] Zhu Yaohui.. Improving the Power Factors of Distribution Network, Optimizing Reactive Allocation [J]. Heihongjiang Technology Information, 2009 (17). 